\title{
An Experimental and Density Functional Theory Study of the Interactions of $\mathrm{CH}_{4}$ with H-ZSM-5
}

\author{
Rustam Z. Khaliullin and Alexis T. Bell \\ Chemical Sciences Division \\ Lawrence Berkeley National Laboratory \\ and \\ Department of Chemical Engineering \\ University of California \\ Berkeley, CA 94720-1462, USA \\ and \\ Vladimir B. Kazansky \\ N.D. Zelinsky Institute of Organic Chemistry \\ Russian Academy of Sciences, \\ Leninsky Prospekt, 47 \\ 117913 Moscow, Russia
}

Submitted to

Journal of Physical Chemistry

August 9, 2001

To whom correspondence should be sent: A. T. Bell, bell@,cchem.berkeley.edu; V. B. Kazansky, vbk@ioc.ac.ru 


\begin{abstract}
The interactions of methane with Brønsted acid sites in H-ZSM-5 were investigated both experimentally and theoretically. Diffuse reflectance infrared spectroscopy was used to acquire spectra for methane adsorbed on H-ZSM-5 at room temperature and at $77 \mathrm{~K}$. Upon adsorption, the $v_{1}$ and $v_{3}$ vibrational bands of methane shift by $-15 \mathrm{~cm}^{-1}$ and $-23 \mathrm{~cm}^{-1}$, respectively, and the vibrational band for $\mathrm{OH}$ groups associated with Brønsted acid sites shifts by $-93 \mathrm{~cm}^{-1}$. Quantum chemical calculations conducted at the DFT level of theory with a $6-31 \mathrm{~g}^{* *++}$ basis set show that the observed shifts for methane are attributable to the effects of the electrostatic field created by the atoms of the zeolite. To represent the influence of the zeolite on the adsorbed methane correctly, it is essential to take into account the effects of the Madelung field, as well as the local effects of the acid center. The calculated shift in the vibrational frequency of the bridging $\mathrm{OH}$ group lies within the range observed experimentally. However, the quantitative agreement of the calculated and observed shift is not as good as that seen for the bands of $\mathrm{CH}_{4}$.
\end{abstract}




\section{Introduction}

Zeolites are widely used as solid acid catalysts in the petroleum and chemical industries as acid catalysts to promote a broad range of reactions involving hydrocarbons, e.g., cracking, isomerization, alkylation. As a consequence, there has been considerable interest in understanding the relationship of the strength and concentration of acid centers to the composition and structure of zeolites. These efforts have involved both experimental and theoretical investigations. ${ }^{1,2,3,4,5,6}$ One of the experimental methods that has proven particularly useful is infrared spectroscopy of adsorbed probe molecules. ${ }^{4}$ This technique can be used to discriminate between different types of Brønsted and Lewis acid centers in zeolites. Shifts in the frequency of the probe molecule can be related to the interaction energy between an active center and the probe molecule, thereby providing information about the strength of the acid center. Infrared spectroscopy can also be used to determine the density of surface sites, if the molar absorption coefficients are known.

Methane is a nearly ideal molecule for probing the properties of Brønsted acid centers in zeolites. $^{4,7}$ Since it is a very weak base its interaction with an acid center does not cause a significant distortion in the electronic properties of the acid center. Because of its structural simplicity and high symmetry, the spectrum of $\mathrm{CH}_{4}$ is easy to interpret. The reduction in symmetry of $\mathrm{CH}_{4}$ upon adsorption gives rise to the appearance of bands not observable in the gas phase spectrum $\mathrm{CH}_{4}$ and to the resolution of multiply degenerate bands. While a large number of studies have been reported on the use of methane to probe the properties of charge-compensating cations in zeolites $8,9,10,11,12,13,14,15,16,17$, few of these efforts have dealt with the interactions of methane with protonic acidic sites. ${ }^{14,15,17}$ The principal changes observed in the spectrum of 
adsorbed methane are a -23 to $-27 \mathrm{~cm}^{-1}$ shift in the vibrational frequency of the symmetric $\mathrm{C}-\mathrm{H}$ stretching band at $2914 \mathrm{~cm}^{-1}\left(v_{1}\right)$, which is IR-forbidden in the free molecule, and a $-20 \mathrm{~cm}^{-1}$ shift in the IR-active, triply degenerate, asymmetric stretching band of $\mathrm{CH}_{4}$ observed in the gas phase at $3016-3020 \mathrm{~cm}^{-1}$.

The origins of the observed changes in the infrared spectrum of $\mathrm{CH}_{4}$ upon interaction of this molecule with cationic centers can be obtained from quantum mechanical simulations. In particular, such calculations van be used to identify the contributions to the observed perturbations in the IR spectrum of the probe molecule due to local adsorbate-site interactions and those due to the crystal field. We are aware of only one publication reporting quantum calculations of IR spectra for $\mathrm{CH}_{4}$ interacting with alkali and alkaline-earth cations in zeolites ${ }^{18}$. While several papers have reported quantum calculations concerning the energetics of hydrogen exchange between methane and zeolitic protons ${ }^{19,20,21}$, the use of quantum-chemical calculations to interpret the infrared spectrum of adsorbed $\mathrm{CH}_{4}$ has not been previously described.

In the present study infrared spectra for $\mathrm{CH}_{4}$ interacting with $\mathrm{H}-\mathrm{ZSM}-5$ were obtained at both room temperature and liquid nitrogen temperature and quantum chemical calculations were carried out to interpret the experimentally obtained spectra. An embedded cluster model was used for the quantum-chemical calculations, which were carried out at the DFT level of theory. As a part of this effort, a refined method was developed for representing the effects of the crystal field on the adsorbed methane. 


\section{Experimental and Theoretical Methods}

\section{Experimental Methods}

The ammonium form of ZSM-5 with a framework Si/Al ratio of 25 was prepared from the sodium form produced by ion exchange with $1 \mathrm{M}$ aqueous solution of $\mathrm{NH}_{4} \mathrm{NO}_{3}$ at room temperature. The degree of sodium exchange by protons was equal to $97 \%$ as measured by atomic absorption spectroscopy of $\mathrm{Na}^{+}$. Decomposition of the ammonium form was performed in vacuum at $673 \mathrm{~K}$ for $4 \mathrm{~h}$ in the same sapphire ampoules that were then used for recording the IR spectrum. The sample was heated from room temperature to the final calcination temperature at $5 \mathrm{~K} / \mathrm{min}$.

Diffuse reflectance infrared Fourier transform (DRIFT) spectra of the powdered zeolite were measured using a Nicolet Impact 410 spectrophotometer equipped with a home-made diffuse reflectance attachment. The ampoule containing the zeolite was maintained at either room temperature or $77 \mathrm{~K}$. For the latter case, a quartz Dewar filled with liquid nitrogen was used to cool the sample. Methane was adsorbed from a large volume at $190 \mathrm{~K}$ at an equilibrium pressure of $1.3 \mathrm{kPa}$. Then the sample was then slowly cooled to $77 \mathrm{~K}$. Measurements at room temperature were performed at different methane pressures. All DRIFT spectra were transformed into Kubelka-Munk units assuming that the reflectivity of the samples at $5000 \mathrm{~cm}^{-1}$ was equal to 0.9 units. After that the background created by the zeolite was subtracted.

\section{Theoretical Methods}

Two theoretical approaches were used to describe the interactions of methane with Brønsted acid centers in H-ZSM-5. The first of these considers only the atoms in a small portion of the zeolite in the immediate vicinity of the acid center. This cluster and the adsorbed methane 
are described quantum chemically. This model is referred to as the cluster model. As discussed below, we found that the electrostatic potential in the vicinity of the adsorbed methane created by the atoms of the cluster can be described accurately by a series of point charges placed at the position of each of the cluster atoms. When this electrostatic representation of the cluster is used in quantum chemical calculations of the vibrational spectrum of methane, it reproduces the spectrum obtained from a fully quantum chemical representation of the cluster and the adsorbed methane. To capture the effects of the Madelung field of the zeolite crystal, we have calculated the effective charges associated with $\mathrm{Si}$ and $\mathrm{O}$ atoms in the lattice and a scheme is then used to embed the electrostatic representation of the acid center in a purely siliceous lattice for MFI. This second model is referred to as the embedded electrostatic cluster model.

The portion of zeolite comprising the acid center was represented by a $5 \mathrm{~T}$ cluster containing 34 atoms (Figure 1a). The terminal oxygen atoms of the cluster were fixed at their crystallographic positions $^{22}$. Dangling bonds were terminated by hydrogen atoms placed in the direction of the next $\mathrm{T}$ site. The lengths of these bonds were optimized during energy minimization while their directions remained fixed. The location of the cluster in H-ZSM-5 was chosen such that the $\mathrm{Al}$ atom is located in the $\mathrm{T}_{7}$ crystallographic site of the orthorhombic modification of ZSM-5 and the charge-compensating proton is associated with the $\mathrm{O}_{17}$ atom. This position was chosen because it is one of the most energetically favorable sites for the $\operatorname{proton}^{23,24,25}$ and because it is located in the sinusoidal channel of ZSM-5 in a position readily accessible by adsorbates.

Becke's three-parameter hybrid exchange functional in combination with the gradientcorrected correlation functional of Lee, Yang and Parr (B3LYP) were used throughout. ${ }^{26}$ Several authors have reported that this functional is the best choice for studies of weak adsorbate- 
adsorbent interactions governed by electrostatic interactions. ${ }^{27,28}$ The $6-31 \mathrm{~g}$ basis set was used for all atoms. To describe the weak van der Waals interactions of methane with an acid center, polarization and diffuse functions were added to all atoms, excluding the terminal $\mathrm{OH}$ groups connected to $\mathrm{Si}$ atoms. The cluster geometry was optimized and the harmonic vibrational frequencies were evaluated using analytical energy derivatives. No corrections were made to the calculated adsorption energy for basis-set superposition. Zero-point energies were computed from the calculated vibrational frequencies, ignoring imaginary frequencies corresponding to vibrations of fixed terminal groups. All calculations were carried out using Jaguar $4.0^{29}$ and Gaussian $98^{30}$ ab initio packages. Coarse optimization was done using the Jaguar program and subsequent refinement and frequencies calculations were carried out using Gaussian 98.

In this work we used the 5T cluster model with a "chain" configuration (Figure 1a), rather than the widely used $5 \mathrm{~T}$ model having a "cross" configuration (Figure 1b). The reason for this is that the "chain" configuration provides a better description of the electrostatic potential in the region of methane adsorption. To confirm that the "chain" configuration provides a good representation for the structure of adsorbed $\mathrm{CH}_{4}$, we compared the minimum energy geometries obtained for the "chain" and "cross" configurations. Such comparison shows that the differences in bond lengths and bond angles of the active site are very small ( $\mathrm{rms}=0.013 \AA, 1.5^{\circ}$; $\left.\max =0.035 \AA, 4.0^{\circ}\right)$.

The cluster model described above accounts only for the local effects of the Brønsted acid proton and the portion of the zeolite in the immediate vicinity of the acid center, but does not represent the effects of the remainder of the zeolite crystal lattice. To do so, requires an accurate and efficient means for describing the electrostatic potential of the crystal field. Several approaches have been described in the literature for embedding a cluster into the crystal lattice. 
The most rigorous embedding scheme takes into account electrostatic Coulombic and exchange contributions between the cluster and the crystal environment as well as other quantum mechanical effects ${ }^{31}$. More commonly, however, only the electrostatic contribution of the zeolite lattice is included in the Hamiltonian for a cluster that is treated quantum mechanically. ${ }^{21,32}$

One of the simplest and most accurate methods for including the electrostatic field of an infinite solid into the Hamiltonian of a cluster model is that developed by Stefanovich and Troung and referred to as SCREEP (Surface Charge Representation of the Electrostatic Embedding Potential) ${ }^{33}$ The Madelung potential of the periodic solid is represented by a finite number of charges located around the site of interest. Two sets of charges are used for this purpose, as shown in Figure 2. The first set of charges is located at the zeolite crystallographic positions within one or several unit cells from the site of interest. These charges lie within what is called the "explicit" zone. The values of these charges are either assumed or are taken from a Mulliken population analysis of the wave functions for $\mathrm{Si}$ and $\mathrm{O}$ atoms determined from periodic-boundary, ab initio calculations for a purely siliceous zeolite framework. ${ }^{21,34,35,36,37}$ The second set of charges is placed on a closed surface that encloses the quantum mechanically treated atoms. These charges, referred to as "surface" charges, are needed to reproduce the potential of the infinite crystal. The magnitude of the surface charges is found by a least-square fit to the exact potential calculated from an Ewald summation for a series of test points lying inside the closed surface. Several options are available for reducing the deviation from the exact Madelung potential to very small values. ${ }^{38}$ The final step in the procedure is to replace the point charges corresponding to the atoms in the cluster by the atoms (e.g., $\mathrm{Si}, \mathrm{Al}, \mathrm{O}$ ) that are to be treated quantum mechanically. In this way the cluster is embedded in the set of point charges representing the zeolite lattice field. Since the cluster is terminated by $\mathrm{H}$ atoms at its periphery, 
the contributions of these atoms to the electrostatic field need to be taken into account, and several methods for doing so have been reported. ${ }^{32}$

In the course of the present study, we found that the effects of the zeolite lattice on vibrational spectrum of adsorbed methane could be handled most effectively by using point charges to represent all portions of the zeolite. The electrostatic field created by these point charges was incorporated into the Hamiltonian used to calculate the vibrational spectrum of $\mathrm{CH}_{4}$ by quantum chemical methods. The means by which point charges are selected to represent the zeolite lattice and the atoms of the cluster are discussed next, together with the method used to insert the cluster into the zeolite lattice.

The electrostatic potential fitting (ESPF) procedure within Jaguar $4.0^{39}$ was used to determine the point charges associated with a purely siliceous lattice of ZSM-5. To do so, DFT/B3LYP calculations were carried out for the purely siliceous cluster shown in Figure 1c, using a $6-31 \mathrm{~g}^{* *++}$ basis set. The potential produced by the nuclei and the electrons associated with this cluster could be reproduced by a set of point charges placed on the atomic centers of the cluster, to an rms level of $7.58 \times 10^{-4}$ hartrees $(1.9 \mathrm{~kJ} / \mathrm{mol})$. For subsequent calculations, the charge on the central $\mathrm{Si}$ atom and the average of the charge on the four surrounding $\mathrm{O}$ atoms of the cluster were used to represent the electrostatic field created by the Si and O atoms of the "explicit" portion of the crystal lattice. The value of the charge on Si is $1.50 \mathrm{e}$ and that on $\mathrm{O}$ is 0.75e. It is notable that the charge on Si lies within the range estimated from various Mulliken population analyses (see Table 1). ${ }^{32,36}$

The ESPF method was also used to determine the appropriate point charges to represent the potential in the vicinity of the Brønsted acid center of the cluster shown in Figure 1a. In this case the rms error in the potential was $9.46 \times 10^{-4}$ hartrees $(2.5 \mathrm{~kJ} / \mathrm{mol})$. We also found that the 
potential generated by the point-charge model of the cluster yielded vibrational frequencies for $\mathrm{CH}_{4}$ that are in excellent agreement with those determined from DFT calculations for the cluster (see Table 2). This agreement provides direct evidence that the IR shifts of $\mathrm{CH}_{4}$ can be predicted correctly, using an electrostatic model with appropriately selected point charges.

To embed the cluster representing the Brønsted acid site into the lattice of ZSM-5, we undertook a modification of the approach described by Troung and coworkers ${ }^{32}$. In the original form of this approach, the charges on the lattice closest to the terminal $\mathrm{H}$ atoms on the cluster are removed. These charges are denoted by an $\mathrm{x}$ in Figure 3a. The charges in the second shell of lattice atoms (the a charges in Figure 3a) are then adjusted to reproduce the potential around the adsorbed molecule, keeping the total charge constant. For this test the mean potential is calculated for a set of 729 test points located in a cube situated in the zone of adsorbed $\mathrm{CH}_{4}$. Embedding a purely siliceous cluster (see Figure 1d) in the manner described above led to an rms deviation in the potential of $144 \mathrm{~kJ} / \mathrm{mol}$. This corresponds to an error of $84 \%$ relative to the mean potential calculated for a reference model of the zeolite lattice. In the reference model the Si and $\mathrm{O}$ atoms of the cluster are located at the positions calculated for the cluster and all remaining $\mathrm{Si}$ and $\mathrm{O}$ atoms are placed in their crystallographic positions. All $\mathrm{Si}$ atoms are assigned a charge of $+1.5 \mathrm{e}$ and all $\mathrm{O}$ atoms are assigned a charge of $-0.75 \mathrm{e}$. We found that much better agreement could be achieved by removing the point charges for the $\mathrm{H}$ atoms terminating the cluster (designated by $\mathrm{x}$ in Figure $3 \mathrm{~b}$ ) and then adjusting the charges on the nearest point charges (designated by a in Figure $3 b$ ). This embedding procedure gives an rms deviation in the mean potential of $1.8 \mathrm{~kJ} / \mathrm{mol}(1 \%)$ and a maximum deviation of $8.1 \mathrm{~kJ} / \mathrm{mol}(5 \%)$.

As a further test of our embedding procedure, we compared the positions and relative intensities of the infrared bands for $\mathrm{CH}_{4}$ adsorbed in silicalite determined for the embedded 
electrostatic cluster and for the reference model of the zeolite. For both sets of calculations the $\mathrm{CH}_{4}$ molecule was placed in the location where it would normally reside if it were interacting with a Brønsted acid site in H-ZSM-5. Table 3 shows excellent agreement between the two models both in terms of the calculated frequency shifts and the relative band intensities. This indicates that embedding scheme described above is valid.

To determine the effects of the zeolite lattice on the infrared spectrum of $\mathrm{CH}_{4}$ adsorbed in H-ZSM-5, we embedded the cluster shown in Figure 1a and used the procedure described above to remove the effects of the terminating $\mathrm{H}$ atoms. We estimate that the deviation of the potential for the embedded electrostatic cluster model from that for a corresponding reference model is less than $6 \%$. This limit is based on the rms deviation for the purely siliceous form of ZSM-5, when one takes into account the contributions from the ESPF procedure, the SCREEP approximation, and the embedding procedure. The deviation for H-ZSM-5 should be smaller than that for silicalite because of the stronger field around the Brønsted-acid proton, which contributes a larger share to the local potential than the charges distributed on the balance of the lattice.

\section{Results and Discussion}

The infrared spectrum of $\mathrm{CH}_{4}$ adsorbed at room temperature is illustrated in Figure 4. Gas-phase $\mathrm{CH}_{4}$ is clearly evidenced by the sharp band at $3016 \mathrm{~cm}^{-1}$ and the associated rotovibrational bands observed below and above this frequency, which correspond to the $\mathrm{P}$ and $\mathrm{R}$ branches of central feature ( $\mathrm{Q}$ branch). The broad band at $3001 \mathrm{~cm}^{-1}$ is attributed to the asymmetric $\mathrm{C}-\mathrm{H}$ stretching vibrations $\left(v_{3}\right)$ of $\mathrm{CH}_{4}$ adsorbed at Brønsted acid sites. The $v_{1}$ band of free $\mathrm{CH}_{4}$ at $2914 \mathrm{~cm}^{-1}$, which is associated with symmetric $\mathrm{C}-\mathrm{H}$ streching vibrations, cannot be 
observed in gas-phase $\mathrm{CH}_{4}$, but is visible as a low-intensity band at $2894 \mathrm{~cm}^{-1}$ when $\mathrm{CH}_{4}$ interacts with the Brønsted acid centers. The band at $3607 \mathrm{~cm}^{-1}$ is attributable to $\mathrm{O}-\mathrm{H}$ stretching vibrations of the Brønsted acid site in H-ZSM- $5 .{ }^{17}$ In the presence of methane, the intensity of this band decreases and a new band appears at $3550 \mathrm{~cm}^{-1}$ for those bridging $\mathrm{OH}$ groups that interact with $\mathrm{CH}_{4}$. Spectra recorded at pressures lower than $100 \mathrm{kPa}$ were qualitatively similar to that shown in Figure 4. With decreasing $\mathrm{CH}_{4}$ pressure, the intensity of the bands in the region of $2800-3200 \mathrm{~cm}^{-1}$ decreases, as does the intensity of the band at $3550 \mathrm{~cm}^{-1}$, and the band at $3607 \mathrm{~cm}^{-1}$ grows in intensity. At a $\mathrm{CH}_{4}$ pressure of $1.3 \mathrm{kPa}$, intensities of the bands for methane are below $0.1 \mathrm{KM}$ units and the intensity of the band at $3607 \mathrm{~cm}^{-1}$ is virtually the same as that observed in the absence of $\mathrm{CH}_{4}$.

Upon $\mathrm{CH}_{4}$ adsorption at $77 \mathrm{~K}$, the spectrum for adsorbed $\mathrm{CH}_{4}$ is readily visible, even when the gas pressure is only $1.3 \mathrm{kPa}$ (Figure 5). The $v_{3}$ band at $3001 \mathrm{~cm}^{-1}$ is accompanied by low and high frequency wings, but there is no evidence for gas-phase $\mathrm{CH}_{4}$. The wings on the $v_{3}$ band are ascribed to hindered rotation of the methane molecules interacting with the Brønsted acid sites. ${ }^{40}$ The $v_{1}$ band at $77 \mathrm{~K}$ is shifted to $2887 \mathrm{~cm}^{-1}$ and is narrower than that observed at room temperature. The larger extent of interaction between $\mathrm{CH}_{4}$ and the Brønsted acid sites in H-ZSM-5 at $77 \mathrm{~K}$ is also evident. The intensity of the band at $3606 \mathrm{~cm}^{-1}$ for unoccupied acid sites is much smaller at the lower temperature, and correspondingly the band at $3513 \mathrm{~cm}^{-1}$ for $\mathrm{CH}_{4}$ associated with Brønsted acid sites is more intense.

The calculated minimum-energy structure of adsorbed $\mathrm{CH}_{4}$ is shown in Figure 1a and selected geometrical parameters are summarized in Table 4. As one can see from this table, distortions of the methane molecule and of the active center are very small. Methane is only slightly flattened in the direction of $\mathrm{C}-\mathrm{H}_{\mathrm{b}}$ bond. The largest changes are for the $\angle \mathrm{H}_{2} \mathrm{CH}_{3}$ angle 
where hydrogen atoms 2 and 3 interact with oxygen atoms of the zeolite framework. It is notable that the hydrogen atoms of methane are oriented in the direction of the oxygen atoms associated with the zeolite. The distance between these atoms is approximately equal to the sum of the van der Waals radii of oxygen and hydrogen.

The ZPE corrected adsorption energy for the cluster model is $8.7 \mathrm{~kJ} / \mathrm{mol}$. This value is significantly lower than the experimental value of $23 \mathrm{~kJ} / \mathrm{mol}$. No attempts were made to determine a BSSE correction, since it is clear that this correction would only decrease the calculated value of the adsorption energy. The results reported here, however, are consistent with those previously reported, and demonstrate that the B3LYP functional underestimates adsorption energies for methane on cationic zeolite sites. ${ }^{18}$

The predicted symmetry of adsorbed methane deviates from pure $\mathrm{C}_{3 \mathrm{v}}$, because of the distortion of the $\mathrm{CH}_{\mathrm{b}} \mathrm{O}_{\mathrm{b}}$ angle from $180^{\circ}$ resulting from the interaction of the $\mathrm{H}$ atoms of $\mathrm{CH}_{4}$ with the $\mathrm{O}$ atoms of the cluster. To estimate differences in energies between other possible methane configurations, we performed single-point calculations for complexes with these configurations. One of the structures calculated is shown in the Figure 1e and corresponds to an approximate two-fold coordination of $\mathrm{CH}_{4}$. Difference in energies between these complexes is very small $(<1.2 \mathrm{~kJ} / \mathrm{mol})$. This points to the possibility that $\mathrm{CH}_{4}$ can occupy several nearly energetically equivalent positions in the vicinity of a Brønsted acid site in H-ZSM-5. A similar conclusion was reached by Ferrari et al. for adsorption complexes of $\mathrm{CH}_{4}$ with alkali metal cations. $^{18}$

Vibrational frequencies for adsorbed methane were calculated using analytical gradients and were scaled by a multiplicative factor found from a least-square fit of the calculated to the experimental frequencies for gas-phase methane. The resulting factor lies in the range of 
$0.96 \pm 0.04$. Frequency shifts for methane are shown in Table 5. Also shown are the shifts observed experimentally for H-ZSM-5 in this study and in previously published studies. Intensities (in units of $\mathrm{KM} / \mathrm{mol}$ ) for each band are given in parentheses. Calculated frequency shifts reported for both the cluster model and the point-charge, electrostatic model. For $v_{1}$, both models give a good approximation of the observed frequency shift; however, the electrostatic model gives a value that is identical to that measured in three of the four experimental studies. In the case of $v_{3}$, it is much harder to compare the theoretical and experimental results, since only one band is observed experimentally but three non-degenerate bands are predicted theoretically. To enable a more careful comparison between theory and experiment, the theoretically predicted bands were fitted to the experimental spectrum after the later was adjusted to remove the portions of the $v_{3}$ band associated with the $\mathrm{P}$ and $\mathrm{R}$ branches of the spectrum and the feature attributed to very weakly interacting non-oriented $\mathrm{CH}_{4}$ molecules. ${ }^{41}$ The procedure used to remove these features was as follows. The spectrum of adsorbed $\mathrm{CH}_{4}$ recorded at $77 \mathrm{~K}$ was fitted in the vicinity of the $v_{3}$ band by four components, as shown in Figure 6a. The components with the highest and lowest frequencies represent the $\mathrm{P}$ and $\mathrm{R}$ branches of $\mathrm{CH}_{4}$. The spacing between these peaks, $93 \mathrm{~cm}^{-1}$, is consistent with the temperature at which the spectra are recorded. A broad component centered at $3032 \mathrm{~cm}^{-1}$ is used to remove the band assigned to the non-oriented methane molecules interacting with the siliceous portions of the zeolite. The remaining band centered at $3000 \mathrm{~cm}^{-1}$ is that due to the $v_{3}$ vibrations of $\mathrm{CH}_{4}$ interacting with Brønsted acid sites. Removal of the spectral components due to the $\mathrm{P}$ and $\mathrm{R}$ branches of freely rotating $\mathrm{CH}_{4}$ and $\mathrm{CH}_{4}$ adsorbed on the siliceous portion of the zeolite, one obtain the spectrum shown in Figure $6 \mathrm{~b}$.

Attempts were made to fit the spectrum shown in Figure $6 \mathrm{~b}$ using the single feature predicted for $v_{1}$ and the three components predicted for $v_{3}$. The positions and relative intensities 
of each band were fixed and only the widths were allowed to vary. Figures $7 \mathrm{a}$ and $7 \mathrm{~b}$ illustrate the best fits obtained for the cluster model (Figure 1a) and the embedded electrostatic cluster model. It is evident that the cluster model correctly predicts the positions of the $v_{1}$ and $v_{3}$ bands, but under-predicts the intensity of the $v_{1}$ band and over-estimates the width of the $v_{3}$ band. By contrast, the electrostatic model correctly predicts the position and intensity of the $v_{1}$ band and the width of the $v_{3}$ band, but the position of the latter feature is off by about $-5 \mathrm{~cm}^{-1}$. Reference to Table 5 indicates that the better fit obtained using the embedded electrostatic cluster model is consequence of both the positions and relative intensities of the $v_{3}$ components predicted by that model.

As seen in Table 5, the interactions of $\mathrm{CH}_{4}$ with the framework of silicalite also influences the spectrum of adsorbed $\mathrm{CH}_{4}$. While Yamazaki et al. ${ }^{14}$ have observed shifts in the $v_{3}$ band for $\mathrm{CH}_{4}$ adsorbed in silicalite, it is not possible to obtain exact values for these shifts from their paper. However, their work does show that the $v_{3}$ band is intense and is shifted by approximately $-20 \mathrm{~cm}^{-1}$ and that the $v_{1}$ band is very weak. These features are captured by the embedded electrostatic cluster model of silicalite, for which the relative intensities of the $v_{1}$ to $v_{3}$ bands is smaller $(\sim 0.14)$ than that for the proton-containing model $(\sim 0.24)$.

Table 5 shows that the $v_{2}$ (symmetric bending vibration) band is expected to be very weak in intensity irrespective of which model is used. This finding is qualitatively consistent with the absence of a $v_{2}$ band in any of the experimental studies, even though the $v_{2}$ band of $\mathrm{CH}_{4}(1534$ $\mathrm{cm}^{-1}$ ) would fall within a region that should be readily observable by diffuse reflectance infrared spectroscopy. 
By contrast, the position of the $v_{4}$ (asymmetric bending vibration) band of $\mathrm{CH}_{4}$ $\left(1306 \mathrm{~cm}^{-1}\right)$ lies just outside the range of observation, since strong phonon bands of the zeolite lattice make it very difficult to observe spectral features below $1300 \mathrm{~cm}^{-1}$. The lack of detailed experimental data on $v_{4}$ vibration for methane on H-ZSM5 zeolite does not allow us to compare our theoretical results with experiment. We note, however, that Cohen de Lara and coworkers have observed a splitting of the $v_{4}$ band into three components when $\mathrm{CH}_{4}$ is adsorbed on $\mathrm{NaA}$ zeolite at cryogenic temperatures. ${ }^{41}$ The high and medium frequency components are blue shifted relative to gas-phase $\mathrm{CH}_{4}$, whereas the low frequency component is red shifted. As seen in Table 5, the calculated shifts for the embedded point-charge model are in qualitative agreement with this observation.

In addition to examining the effect of adsorption on the vibrational spectrum of $\mathrm{CH}_{4}$, we estimated the effect of $\mathrm{CH}_{4}$ adsorption on the vibrational frequency of the bridging $\mathrm{O}-\mathrm{H}$ group, which constitutes the Brønsted acid site. The calculated shift in the vibrational frequency of the Brønsted acid OH group using the $6-31 \mathrm{~g}^{* *++}$ basis set was $-66 \mathrm{~cm}^{-1}$ for the configuration of $\mathrm{CH}_{4}$ shown in Figure 1a. This value lies between the experimentally observed values of $-57 \mathrm{~cm}^{-1}$ and $-93 \mathrm{~cm}^{-1}$ observed at room temperature and $77 \mathrm{~K}$, respectively, seen in Figures 4 and 5. Since the quantum calculations are effectively for $0 \mathrm{~K}$, it is more appropriate to compare the predicted shift with that observed at $77 \mathrm{~K}$. The under prediction of the shift may well be due to the under prediction of the adsorption energy, since a tighter binding of the $\mathrm{CH}_{4}$ molecule would have led to a weakening of the $\mathrm{O}-\mathrm{H}$ bond and a further red shift in its vibrational frequency. 


\section{Conclusions}

Adsorption of methane on the Brønsted acid sites of H-ZSM-5 results in a shift of the $v_{1}$ and $v_{3}$ vibrational bands of methane by $-15 \mathrm{~cm}^{-1}$ and $-23 \mathrm{~cm}^{-1}$, respectively. A shift of $-93 \mathrm{~cm}^{-1}$ was observed in the O-H vibrational frequency for the Brønsted acid center. Quantum chemical calculations demonstrate that these shifts are attributable to the effects of the electrostatic field created by the atoms in the zeolite on the adsorbed methane. The observed frequency shifts in the $v_{1}$ and $v_{3}$ bands and their relative intensities are well described by an embedded electrostatic cluster model of the zeolite. In this model both the Brønsted acid site and the atoms are of the zeolite lattice are represented by an appropriate set of point charges. Exclusion of the Madelung field from the calculations leads to a poorer representation of the experimentally observed spectrum of adsorbed methane. The methods used in this study under predict the observed heat of adsorption for $\mathrm{CH}_{4}$ and the shift in the vibrational frequency for bridging $\mathrm{OH}$ group of the Brønsted acid center.

\section{Acknowledgments}

This work was supported by a grant from the Civilian Research and Development Foundation under grant RC1-2204 and by the Director of the Office of Basic Energy Sciences, Chemical Sciences Division, of the U.S. Department of Energy under contract DE-AC03-76SF00098. The authors would like to acknowledge A. I. Serkyh for the acquisition of the infrared spectra reported here, T. N. Troung and P. Treesukol for their assistance with the implementation of the SCREEP procedure, and V.N. Solkan for discussion of the theoretical methods used in this work. 


\section{References}

\footnotetext{
${ }^{1}$ Martines, J.A.; Souverijns, W.; van Rhijn, W.; Jacobs, P.A. in Handbook of Heterogeneous Catalysis, Ertl, G.;

Knözinger, H.; Weitkamp, J. vol. 1, Weinheim: VCH, 1997, p. 324

${ }^{2}$ Corma, A. Chem. Rev., 1995, 95, 559

${ }^{3}$ Farneth, W. E.; Gorte, R.J. Chem. Rev., 1995, 95, 615

${ }^{4}$ Knözinger, H.; Huber, S. J. Chem. Soc., Faraday Trans., 1998, 94, 2047

${ }^{5}$ van Santen, R.A.; Kramer, G.J. Chem. Rev., 1995, 95, 637

${ }^{6}$ Hattori, H. Chem. Rev., 1995, 95, 537

${ }^{7}$ Zhlobenko, V.L.; Kustov, L.M.; Kazansky, V.B. Dokl. Akad. Nauk SSSR, 1988, 300, 384

${ }^{8}$ Cohen De Lara, E.; Delaval, Y. J. Phys. Chem., 1974, 78, 2180

${ }^{9}$ Cohen De Lara, E.; Seloudoux, R. J. Chem. Soc., Faraday Trans. I, 1983, 79, 2271

${ }^{10}$ Sousson-Jacob, J.; Goulay, A.M.; Cohen de Lara, E. Mol. Phys., 1992, 76, 1037

${ }^{11}$ Cohen de Lara, E.; Goulay, A.M.; Sousson-Jacob, J.; Kahn, R. Mol. Phys., 1992, 76, 1049

${ }^{12}$ Cohen De Lara, E.; Kahn, R.; Seloudoux, R. J. Chem. Phys., 1985, 83, 2646

${ }^{13}$ Yamazaki, T.; Abo, Y.; Watanuki, I.; Ding, T.; Ozava, S.; Ogino, Y. Chem. Lett., 1987, 7, 1457

${ }^{14}$ Yamazaki, T.; Watanuki, I.; Ozava, S.; Ogino, Y. Langmuir., 1988, 4, 433

${ }^{15}$ Khodakov, A.Yu.; Kustov, L.M.; Kazansky, V.B.; Williams, C. J. Chem. Soc., Faraday Trans., 1993, 89, 1393

${ }^{16}$ Huber, S.; Knözinger, H. Chem. Phys. Lett, 1995, 244, 111

${ }^{17}$ Chen, L.; Lin, L.; Xu, Z.; Zhang, T.; Xin, Q.; Ying, P.; Li, G.; Li, C. J. Catal. 1996, 161, 107

${ }^{18}$ Ferrari, A.M.; Neyman, K.M.; Huber, S.; Knözinger, H.; Rösch, N. Langmuir, 1998, 14, 5559

${ }^{19}$ Kramer, G.J.; van Santen, R.A. J. Am. Chem. Soc., 1995, 117, 1766

${ }^{20}$ Curtiss, L.A.; Zygmunt, S.A.; Iton, L.E. Proc. Int. Zeolite Conf. $12^{\text {th }}, \mathbf{1 9 9 9}, 1,415$

${ }^{21}$ Vollmer, J.M.; Truong, T.N. J. Phys. Chem. B, 2000, 104, 6308

${ }^{22}$ van Koningsveld, H.; van Bekkum, H.; Jansen, J.C. Acta Cryst., 1987, B43, 127

${ }^{23}$ Ricchiardi, G.; Newsam, J.M. J.Phys.Chem. B, 1997, 101, 9943

${ }^{24}$ Eichler, U.; Brändle, M.; Sauer, J. J.Phys.Chem. B, 1997, 101, 10035

${ }^{25}$ Nachtigallová, D.; Nachtigall, P.; Sierka, M.; Sauer, J. Phys. Chem. Chem. Phys., 1999, 1, 2019
} 
${ }^{26}$ Parr, R. G.; Yang, W. Density-Functional Theory of Atoms and Molecules; Oxford University Press: Oxford,

U.K., 1989

${ }^{27}$ Ferrari, A. M.; Ugliengo, P.; Garrone, E. J. Chem. Phys., 1996, 105, 4129

${ }^{28}$ Civalleri, B.; Garrone, E.; Ugliengo, P. J. Mol. Struct. (THEOCHEM), 1997, 419, 227

${ }^{29}$ Jaguar 4.0, Schrodinger, Inc., Portland, Oregon, 2000

${ }^{30}$ Gaussian 98, Revision A.3, Frisch, M. J.; Trucks, G. W.; Schlegel, H. B.; Scuseria, G. E.; Robb, M. A.;

Cheeseman, J. R.; Zakrzewski, V. G.; Montgomery, J. A.; Stratmann, Jr., R. E.; Burant, J. C.; Dapprich, S.; Millam, J. M.; Daniels, A. D.; Kudin, K. N.; Strain, M. C.; Farkas, O.; Tomasi, J.; Barone, V.; Cossi, M.; Cammi, R. ;

Mennucci, B.; Pomelli, C.; Adamo, C.; Clifford, S.; Ochterski, J.; Petersson, G. A.; Ayala, P. Y.; Q. Cui,;

Morokuma, K.; Malick, D. K.; Rabuck, A. D.; Raghavachari, K.; Foresman, J. B.; Cioslowski, J.; Ortiz, J. V.;

Stefanov, B. B.; Liu, G.; Liashenko, A.; Piskorz, P.; Komaromi, I.; Gomperts, R.; Martin, R. L.; Fox, D. J.; Keith,

T.; Al-Laham, M. A.; Peng, C. Y.; Nanayakkara, A.; Gonzalez, C.; Challacombe, M.; Gill, P. M. W.; Johnson, B.;

Chen, W.; Wong, M. W.; Andres, J. L.; Gonzalez, C.; Head-Gordon, M.; Replogle, E. S.; Pople, J. A. Gaussian, Inc., Pittsburgh PA, 1998.

${ }^{31}$ Pisani, C.; Birkenheuer, U. Int. J. Quantum Chem., 1995, S29, 221

${ }^{32}$ Vollmer, J.M.; Stefanovich, E. V.; Troung, T.N. J. Phys. Chem. B, 1999, 103, 9415

${ }^{33}$ Stefanovich, E.V.; Truong, T.N. J. Phys. Chem. B, 1998, 102, 3018

${ }^{34}$ Cook, S.J.; Chakraborty, A.K.; Bell, A.T.; Theodorou, D.N. J. Phys.Chem. 1993, 97, 6679

${ }^{35}$ White, J.C.; Hess, A.C. J. Phys.Chem. 1993, 97, 8703

${ }^{36}$ Kyrlidis, A.; Cook S.J.; Chakraborty, A.K.; Bell, A.T.; Theodorou, D.N. J. Phys.Chem. 1995, 99, 1505

${ }^{37}$ Limtrakul, J.; Khongpracha, P.; Jungsuttiwong S.; Troung T.N. J. Mol. Catal.: Chem 2000, 153, 155

${ }^{38}$ The source code for the SCREEP program is available from Prof. T. N. Troung upon request: truong@chemistry.chem.utah.edu

${ }^{39}$ Wright J. R. Jaguar User's Guide, Version 3.5, July 1998, p. 47

${ }^{40}$ Sheppard, N.; Yates, D. J. C. Proc. Roy. Soc. Ser. A 1956, 238, 69

${ }^{41}$ Cohen De Lara, E.; Soussen, J.; Goulay, A.-M. Mol. Phys., 1999, 96, 987 
Figure 1. Cluster models representing active site in H-ZSM-5 zeolite and silicalite

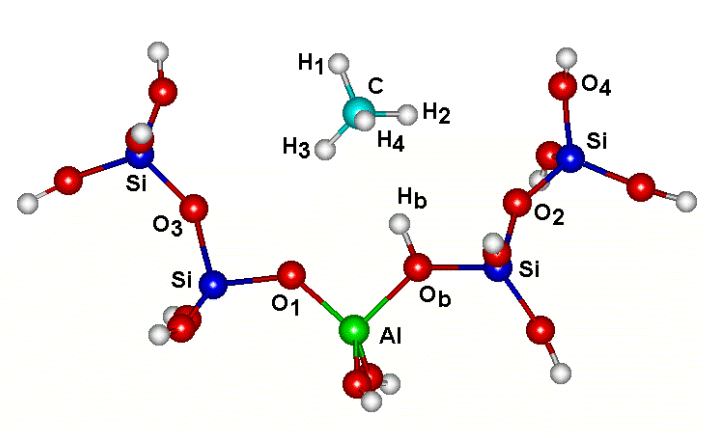

(a)

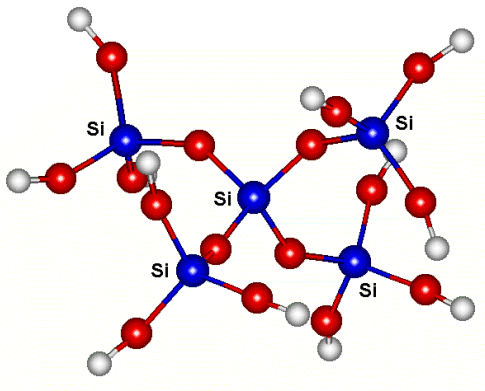

(c)

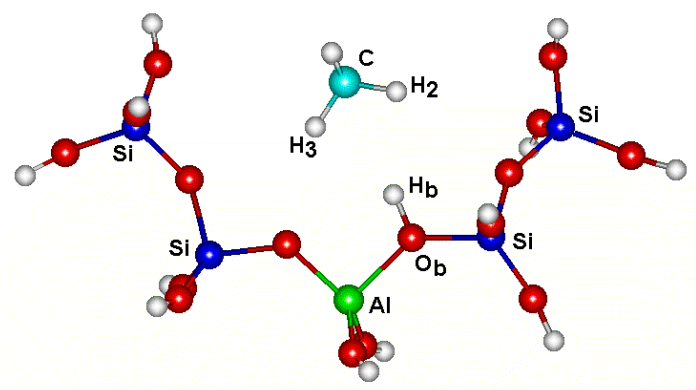

(e)

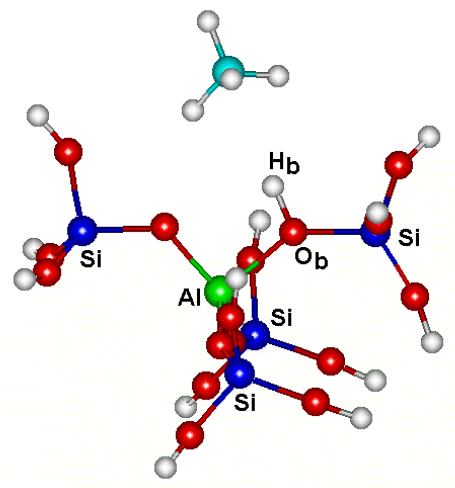

(b)

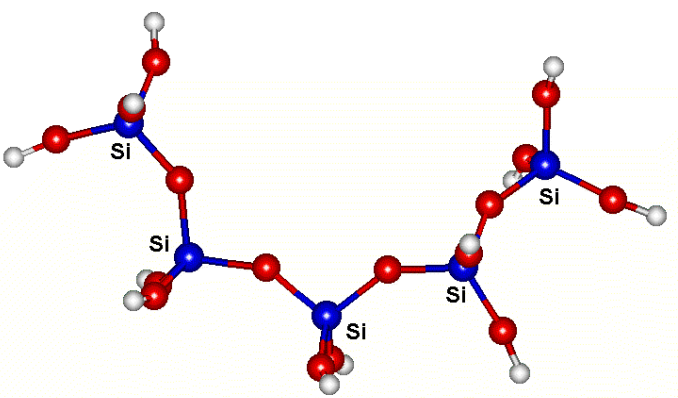

(d) 
Figure 2. SCREEP embedding scheme
-
$0^{-} \odot$
$\bullet$

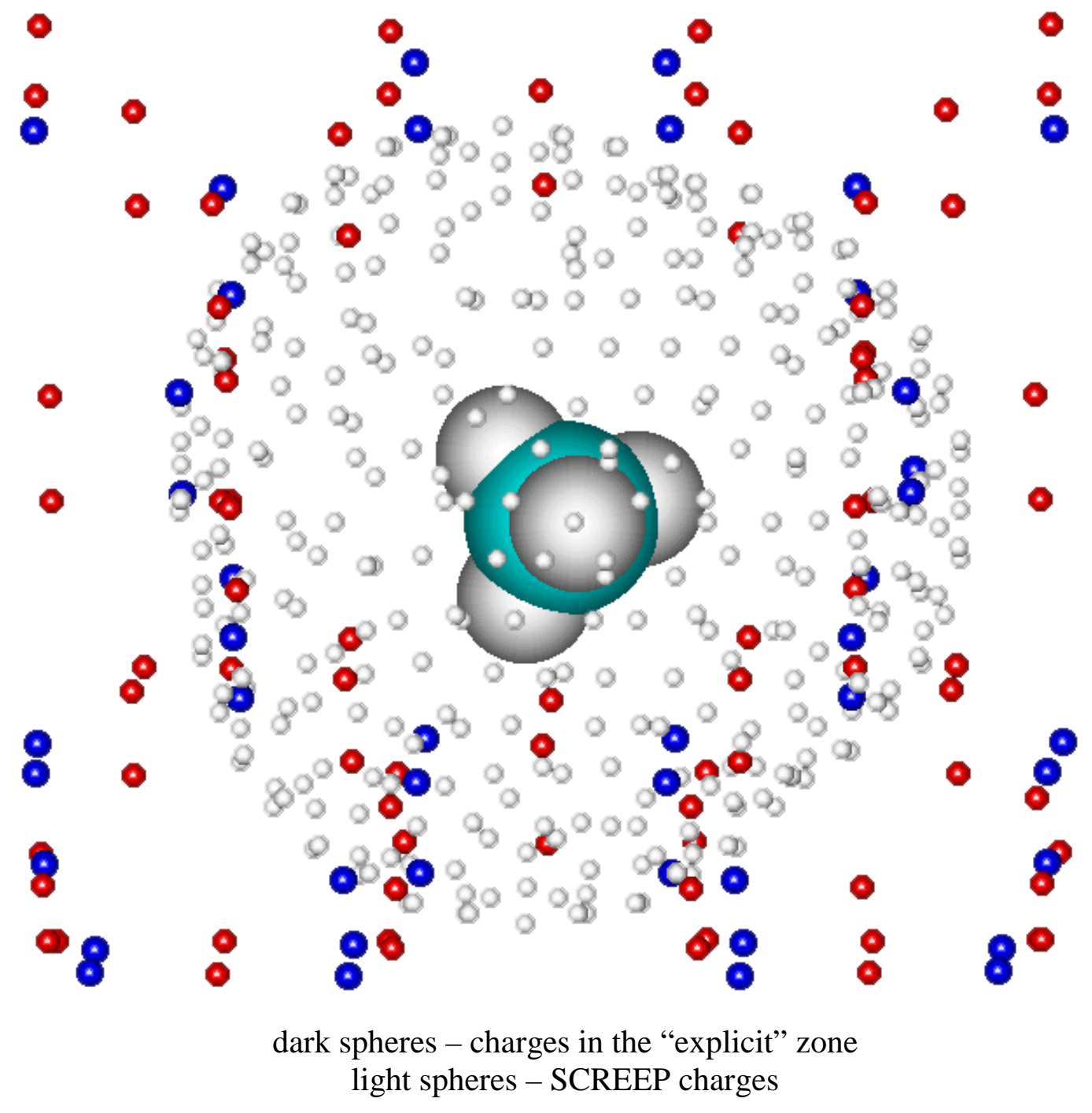


Figure 3. Treatment of boundary effects upon embedding

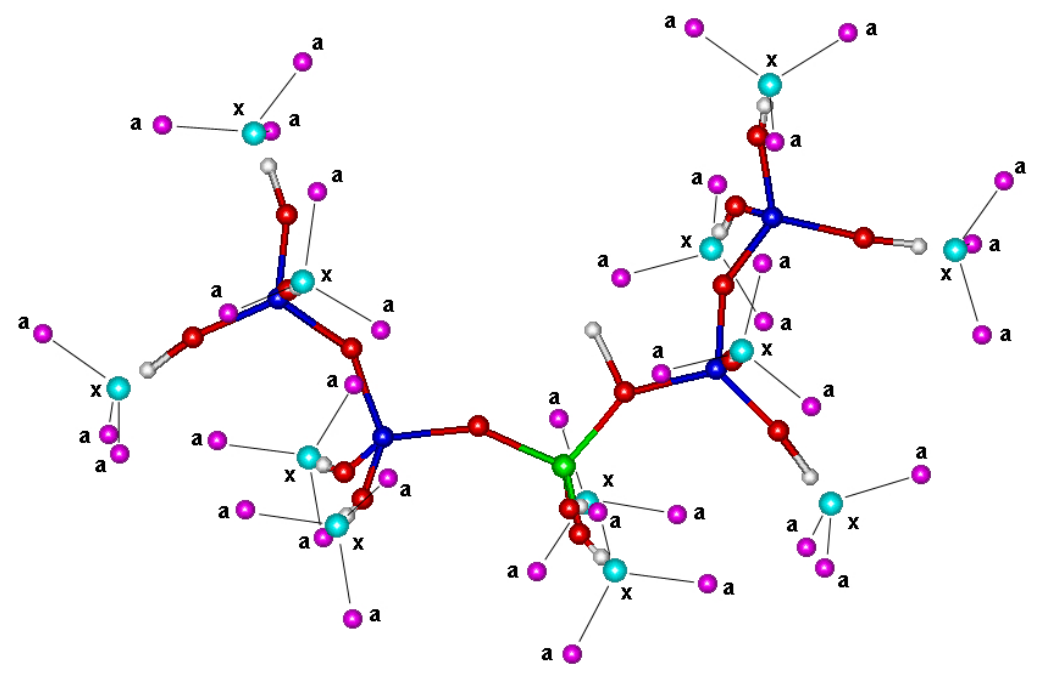

(a) Scheme used in ref. 32

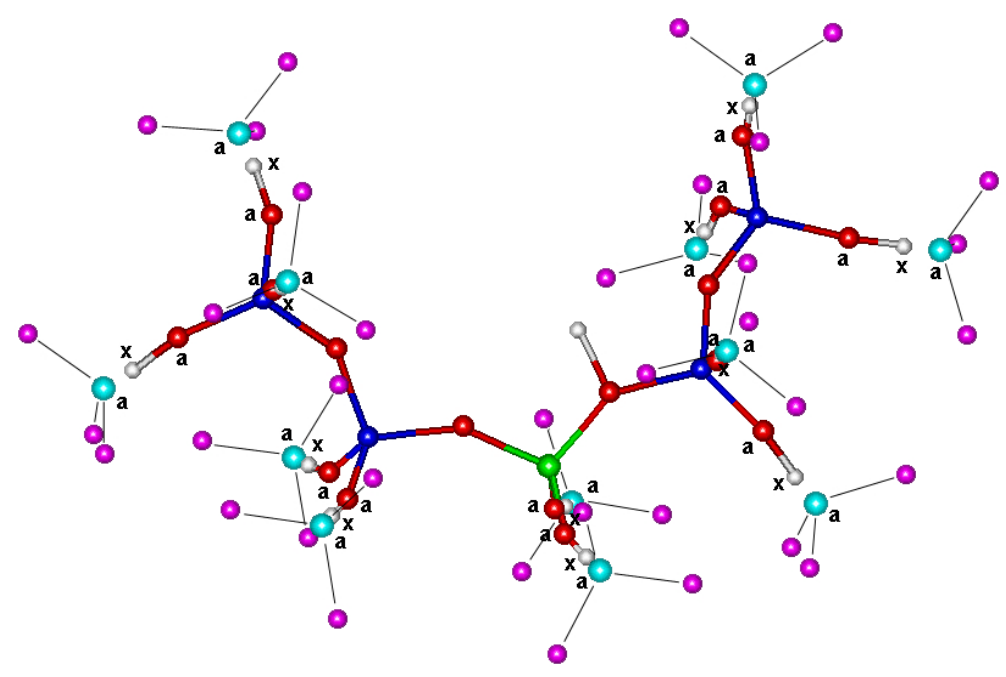

(b) Scheme used in this work

$\mathrm{x}$-charges to remove, a-charges to adjust 
Figure 4. Methane adsorbed on H-ZSM5. Temperature, $298 \mathrm{~K}$; methane pressure $100 \mathrm{kPa}$

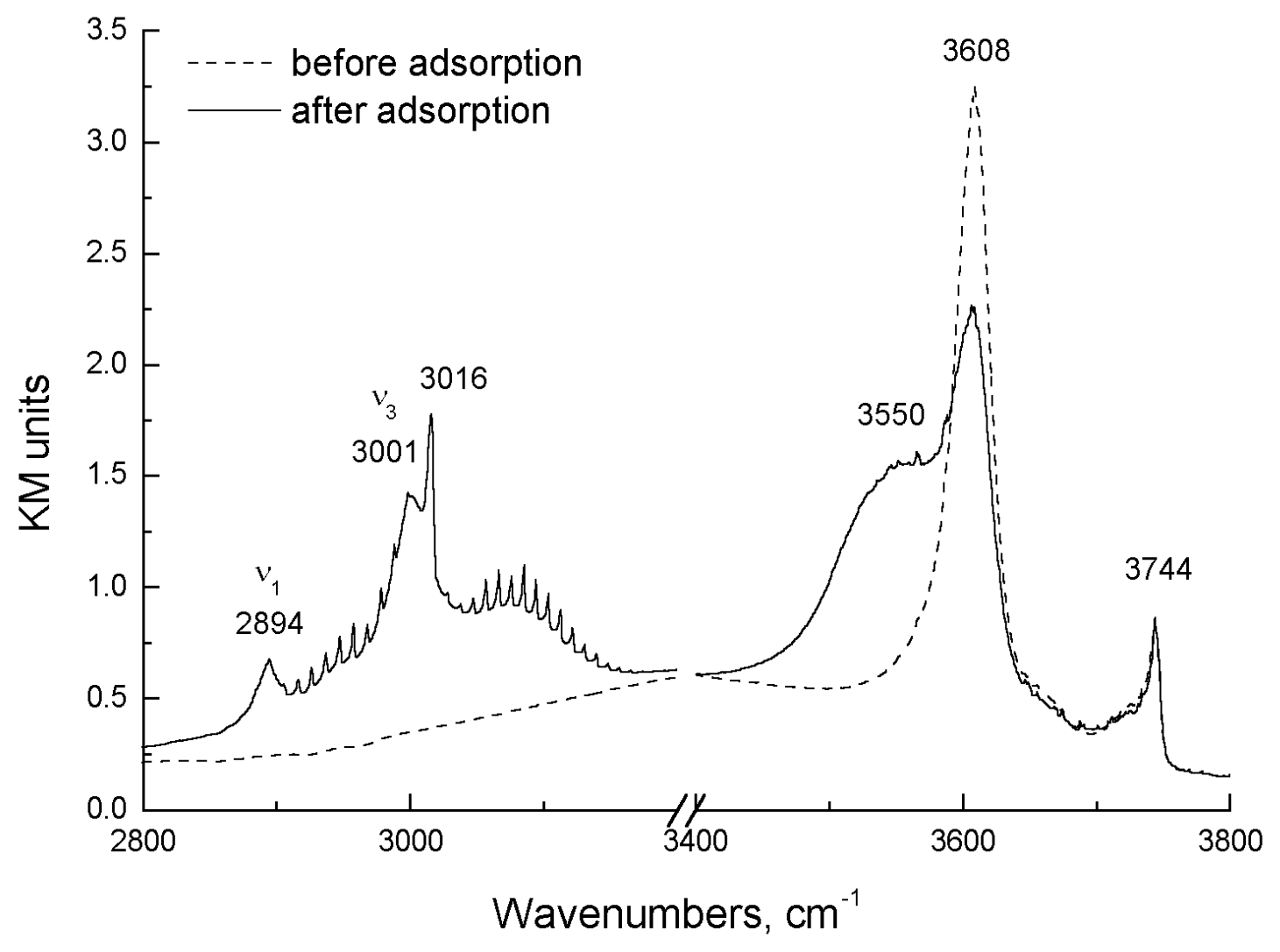


Figure 5. Methane adsorbed on H-ZSM5. Temperature, $77 \mathrm{~K}$; methane pressure $1.3 \mathrm{kPa}$

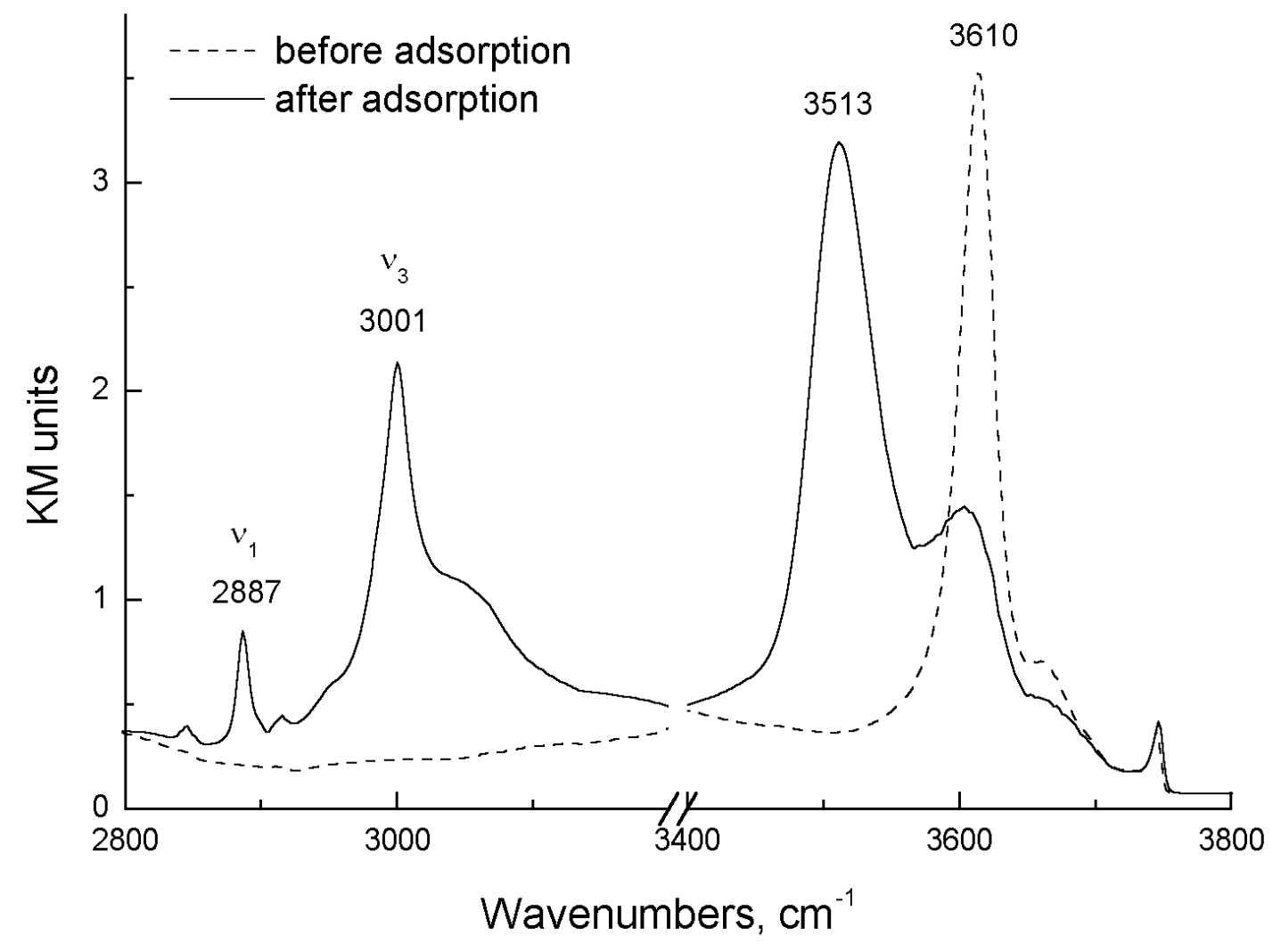


Figure 6a. Profile and spectral decomposition of the experimental spectrum

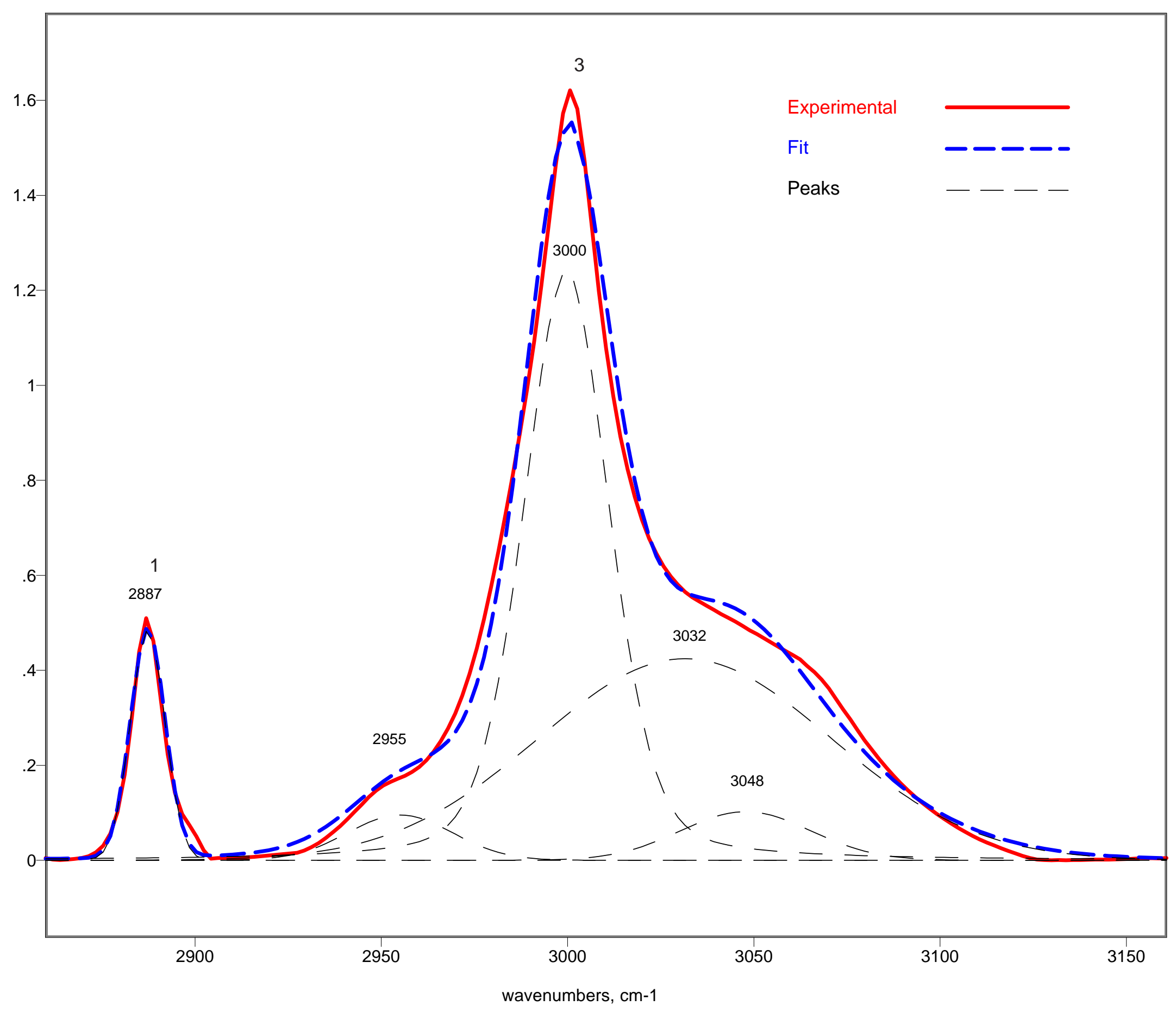


Figure 6b. 1 and 3 spectral components

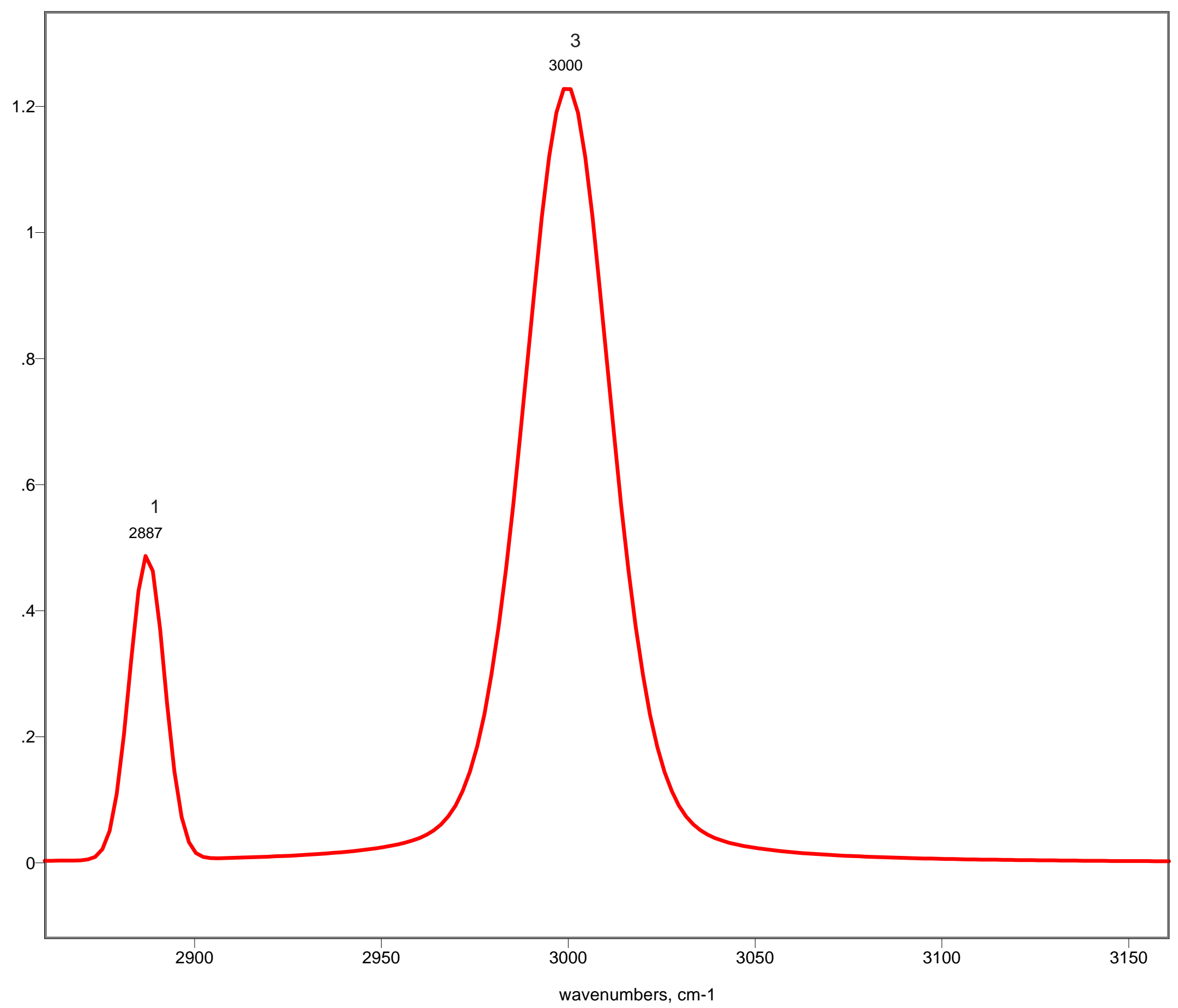


Figure 7a. Comparison of the experimental spectrum of adsorbed methane and the spectrum calculated using the cluster model

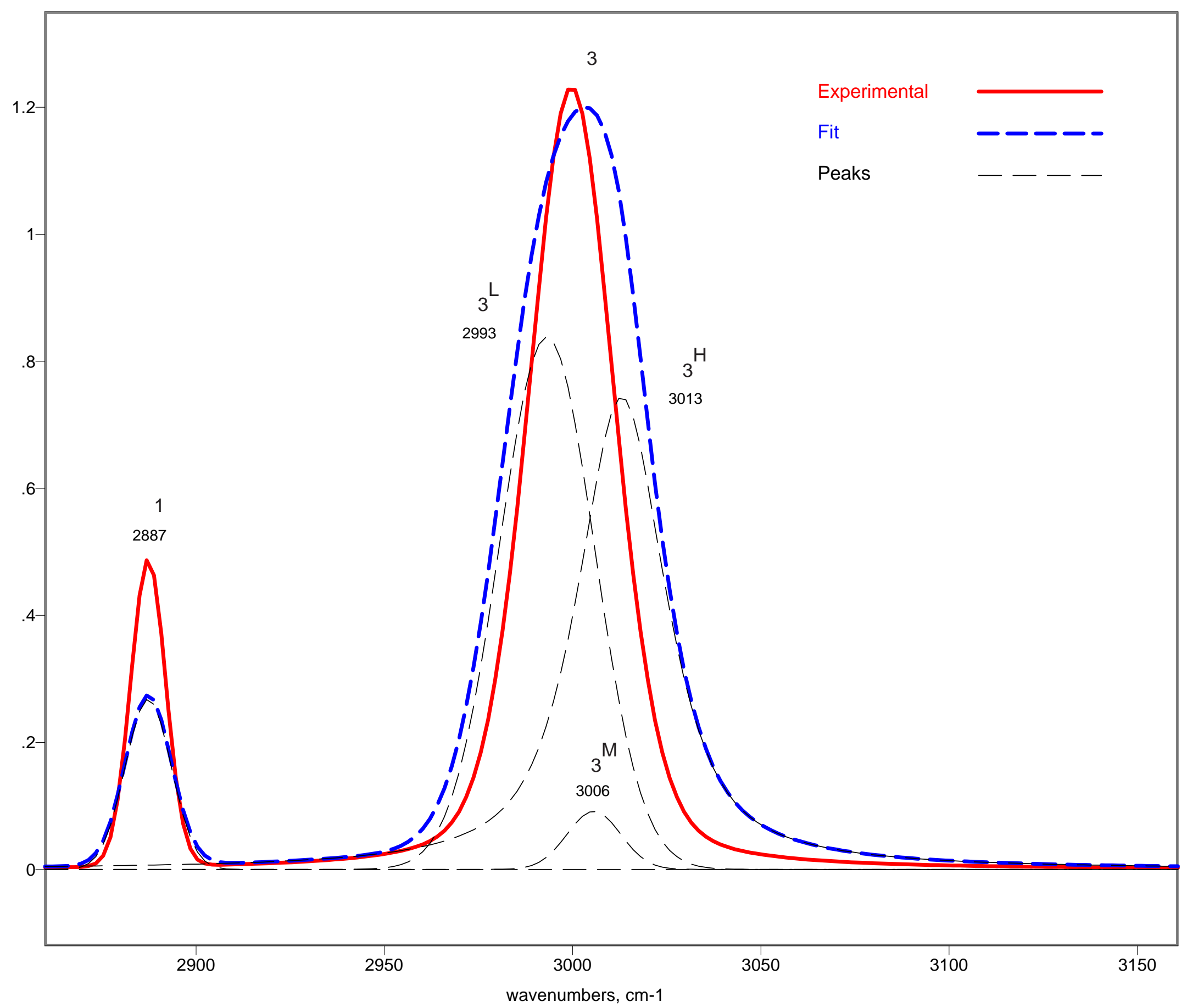


Figure 7b. Comparison of the experimental spectrum of adsorbed methane and the spectrum calculated using the embedded electrostatic cluster model

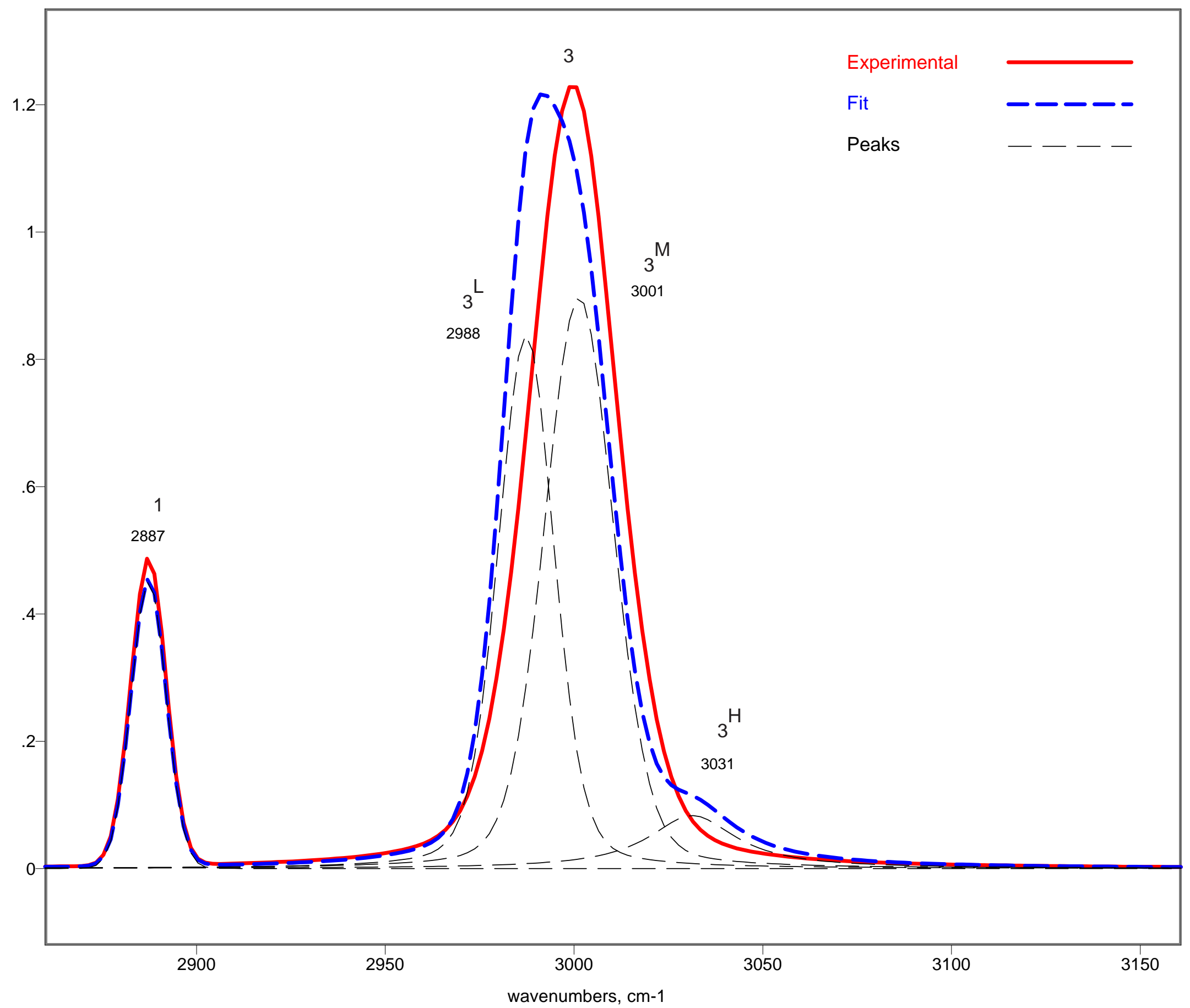


Table 1. Lattice charges for Si used by different authors for embedding clusters

\begin{tabular}{|l|c|c|}
\hline \multicolumn{1}{|c|}{ Method of charge determination } & $\mathrm{q}(\mathrm{Si})$ & Reference \\
\hline Mulliken charges from cluster wave function for ZSM-5 & 2.18 & 34 \\
\hline Mulliken charges from cluster wave function for ZSM-5 & 1.42 & 36 \\
\hline Mulliken charges from periodic HF wave function for sodalite & 1.97 & 21,37 \\
\hline Mulliken charges from periodic HF wave function for ZSM5 & 1.48 & 35 \\
\hline
\end{tabular}

Table 2. Comparison of shifts of vibrational frequencies for methane calculated for $\mathrm{ab}$ initio and electrostatic clusters

\begin{tabular}{|l|c|c|c|c|c|c|c|c|c|}
\hline & $v_{4}{ }^{\mathrm{l}}$ & $v_{4}{ }^{\mathrm{m}}$ & $v_{4}{ }^{\mathrm{h}}$ & $v_{2}{ }^{\mathrm{l}}$ & $v_{2}{ }^{\mathrm{h}}$ & $v_{1}$ & $v_{3}{ }^{\mathrm{l}}$ & $v_{3}{ }^{\mathrm{m}}$ & $v_{3}{ }^{\mathrm{h}}$ \\
\hline ab initio cluster & 0 & 3 & 25 & 7 & 15 & -22 & -28 & -16 & -8 \\
\hline ES cluster & -3 & 3 & 28 & 6 & 17 & -19 & -26 & -14 & -4 \\
\hline
\end{tabular}

Table 3. Shifts in infrared frequencies and band intensities (shown in parentheses) for electrostatic representations of silicalite crystal

\begin{tabular}{|l|c|c|c|c|c|c|c|c|c|}
\hline & $v_{4}{ }^{\mathrm{l}}$ & $v_{4}{ }^{\mathrm{m}}$ & $v_{4}{ }^{\mathrm{h}}$ & $v_{2}{ }^{\mathrm{N}}$ & $v_{2}{ }^{\mathrm{h}}$ & $v_{1}$ & $v_{3}{ }^{\mathrm{N}}$ & $v_{3}{ }^{\mathrm{m}}$ & $v_{3}{ }^{\mathrm{h}}$ \\
\hline $\begin{array}{l}\text { reference model } \\
\text { embedded ES } \\
\text { cluster }\end{array}$ & $-27(18)$ & $0(21)$ & $26(22)$ & $-5(2)$ & $5(1)$ & $-7(13)$ & $-19(54)$ & $-5(32)$ & $10(3)$ \\
\hline
\end{tabular}

Table 4. Selected geometry parameters calculated for cluster models shown in Figure 1a

\begin{tabular}{|c|c|c|c|c|c|c|c|c|c|}
\hline $\begin{array}{c}\text { parameter } \\
\AA \text { or Deg }\end{array}$ & $\mathrm{HZ}$ & $\mathrm{CH}_{4}$ & $\mathrm{HZ}+\mathrm{CH}_{4}$ & $\Delta$ & $\begin{array}{c}\text { parameter } \\
\AA \text { or Deg }\end{array}$ & $\mathrm{HZ}$ & $\mathrm{CH}_{4}$ & $\mathrm{HZ}+\mathrm{CH}_{4}$ & $\Delta$ \\
\hline $\mathrm{H}_{\mathrm{b}}-\mathrm{O}_{\mathrm{b}}$ & 0.973 & & 0.976 & 0.003 & $\angle \mathrm{H}_{2} \mathrm{CH}_{3}$ & & 109.5 & 112.2 & 2.7 \\
\hline $\mathrm{Al}-\mathrm{O}_{\mathrm{b}}$ & 1.831 & & 1.828 & -0.003 & $\angle \mathrm{H}_{2} \mathrm{CH}_{4}$ & & 109.5 & 109.4 & -0.1 \\
\hline $\mathrm{Si}-\mathrm{O}_{\mathrm{b}}$ & 1.683 & & 1.683 & 0.000 & $\angle \mathrm{H}_{3} \mathrm{CH}_{4}$ & & 109.5 & 109.3 & -0.2 \\
\hline$\angle \mathrm{AlO} \mathrm{b}_{\mathrm{bi}} \mathrm{Si}$ & 134.6 & & 134.0 & -0.6 & $\mathrm{C}_{-}-\mathrm{H}_{\mathrm{b}}$ & & & 2.500 & \\
\hline$\angle \mathrm{AlO} \mathrm{SiH}_{\mathrm{b}}$ & 170.3 & & 164.3 & -6.0 & $\mathrm{H}_{2}-\mathrm{H}_{\mathrm{b}}$ & & & 2.210 & \\
\hline $\mathrm{C}_{-}-\mathrm{H}_{1}$ & & 1.094 & 1.094 & 0.000 & $\mathrm{H}_{3}-\mathrm{H}_{\mathrm{b}}$ & & & 2.166 & \\
\hline $\mathrm{C}-\mathrm{H}_{2}$ & & 1.094 & 1.097 & 0.003 & $\angle \mathrm{CH}_{\mathrm{b}} \mathrm{O}_{\mathrm{b}}$ & & & 157.0 & \\
\hline $\mathrm{C}-\mathrm{H}_{3}$ & & 1.094 & 1.096 & 0.002 & $\mathrm{H}_{2}-\mathrm{O}_{2}$ & & & 2.886 & \\
\hline $\mathrm{C}-\mathrm{H}_{4}$ & & 1.094 & 1.095 & 0.001 & $\mathrm{H}_{2}-\mathrm{O}_{4}$ & & & 3.261 & \\
\hline$\angle \mathrm{H}_{1} \mathrm{CH}_{2}$ & & 109.5 & 108.3 & -1.1 & $\mathrm{H}_{3}-\mathrm{O}_{1}$ & & & 2.660 & \\
\hline$\angle \mathrm{H}_{1} \mathrm{CH}_{3}$ & & 109.5 & 108.1 & -1.4 & $\mathrm{H}_{3}-\mathrm{O}_{3}$ & & & 2.937 & \\
\hline$\angle \mathrm{H}_{1} \mathrm{CH}_{4}$ & & 109.5 & 109.5 & 0.0 & & & & & \\
\hline
\end{tabular}


Table 5. Calculated and observed shifts in the vibrational bands of adsorbed methane and calculated relative band intensities

\begin{tabular}{|c|c|c|c|c|c|c|c|}
\hline & \multicolumn{3}{|c|}{ Calculated } & \multicolumn{4}{|c|}{ Experimental } \\
\hline & $\begin{array}{c}\text { embedded } \\
\text { ES } \\
\text { silicalite } \\
\end{array}$ & $\begin{array}{l}\text { embedded } \\
\text { ES } \\
\text { H-ZSM-5 }\end{array}$ & $\begin{array}{c}\text { ab initio } \\
\text { cluster } \\
\text { H-ZSM-5 }\end{array}$ & $226 K^{14}$ & $\begin{array}{c}173 \mathrm{~K} \\
1.6 \mathrm{kPa}^{17}\end{array}$ & $\begin{array}{c}300 \mathrm{~K}, \\
4.0 \mathrm{kPa}^{15}\end{array}$ & $\begin{array}{c}77 \mathrm{~K}, \\
1.3 \mathrm{kPa}\end{array}$ \\
\hline$\Delta v_{4}$ & $-29(18)$ & $-49(26)$ & $0(44)$ & N/A & -3 & $\mathrm{~N} / \mathrm{A}$ & $\mathrm{N} / \mathrm{A}$ \\
\hline & $1(21)$ & $27(25)$ & $3(20)$ & & & & \\
\hline & $25(22)$ & $32(29)$ & $24(17)$ & & & & \\
\hline$\Delta v_{2}$ & $-6(3)$ & $-5(4)$ & $6(0)$ & $\mathrm{N} / \mathrm{A}$ & $\begin{array}{c}\text { not } \\
\text { observed }\end{array}$ & N/A & $\mathrm{N} / \mathrm{A}$ \\
\hline & $4(1)$ & $9(3)$ & $14(3)$ & & & & \\
\hline$\Delta v_{1}$ & $-7(13)$ & $-23(17)$ & $-21(8)$ & -23 & -24 & -14 & -23 \\
\hline$\Delta v_{3}$ & $-19(54)$ & $-34(32)$ & $-27(25)$ & $\mathrm{N} / \mathrm{A}$ & -18 & -20 & -15 \\
\hline & $-5(34)$ & $-21(34)$ & $-15(3)$ & & & & \\
\hline & $11(2)$ & $9(3)$ & $-8(22)$ & & & & \\
\hline
\end{tabular}




\section{Figures legends}

Figure 1. Cluster models representing active site in H-ZSM-5 zeolite and silicalite

Figure 2. SCREEP embedding scheme

Figure 3. Treatment of boundary effects upon embedding

Figure 4. Methane adsorbed on H-ZSM5. Temperature, 298K; methane pressure $100 \mathrm{kPa}$

Figure 5. Methane adsorbed on H-ZSM5. Temperature, 77K; methane pressure $1.3 \mathrm{kPa}$

Figure 6a. Profile and spectral decomposition of the experimental spectrum

Figure $6 \mathrm{~b} . v 1$ and $v 3$ spectral components

Figure 7a. Comparison of the experimental spectrum of adsorbed methane and the spectrum calculated using the cluster model

Figure $7 \mathrm{~b}$. Comparison of the experimental spectrum of adsorbed methane and the spectrum calculated using the embedded electrostatic cluster model 